\title{
Antibacterial Activity of Copper-doped Montmorillonite Nanocomposites Prepared by Alkaline Ion Exchange Method
}

\author{
Hamideh Pourabolghasem, ${ }^{1}$ Mohammad Ghorbanpour ${ }^{2 *}$ and Razieh Shayegh ${ }^{2}$ \\ ${ }^{1}$ Department of Food Science, Islamic Azad University-Sarab Branch, Sarab, Iran \\ ${ }^{2}$ Chemical Engineering Department, University of Mohaghegh Ardabili, Ardabil, Iran \\ *Corresponding author: ghorbanpour@uma.ac.ir
}

Published online: 25 August 2016

To cite this article: Pourabolghasem, H., Ghorbanpour, M. \& Shayegh, R. (2016). Antibacterial activity of copper-doped montmorillonite nanocomposites prepared by alkaline ion exchange method. J. Phys. Sci., 27(2), 1-12, DOI: 10.21315/jps2016.27.2.1

To link to this article: http://dx.doi.org/10.21315/jps2016.27.2.1

\begin{abstract}
The antibacterial activity of copper-doped montmorillonite nanocomposites (Cu-MMT) has been investigated. Copper loaded clay nanocomposites have been synthesised by alkaline ion exchange processes in media containing copper sulfate at $550^{\circ} \mathrm{C}$. Characterisation studies on the composites were done by X-ray diffractometry $(X R D)$, scanning electron microscope (SEM) and absorption spectra analysis. SEM results indicated the diffusion of copper to the inner montmorillonite layer and opening of presenting cracks on its surface. The XRD analysis showed the presence of copper oxide $(\mathrm{CuO})$ structure intercalated within the clay mineral layers. The antimicrobial effects of doped montmorillonite powders against pathogen bacterial strains Escherichia coli and Staphylococcus aureus were tested in broth media. Quantitative test in liquid media clearly showed that copper-doped samples had viable cells reduction ability for testing strains. The excellent antimicrobial activity of the composites was observed on S. aureus. In addition, the composite showed good stability in water and good promise for use in water treatment.
\end{abstract}

Keywords: Antibacterial activity, $\mathrm{Cu}-\mathrm{MMT}$, alkaline ion exchange, nanocomposite

\section{INTRODUCTION}

Antimicrobial materials have the ability of inhibiting the growth or even killing certain types of microorganisms. The search for products with antimicrobial properties has gained particular importance in various operations, such as in raw materials for cosmetics and pharmaceuticals, hospital and veterinary products, food manufacture and animal feeding, among others. To attribute antibacterial properties to an inert material, it is necessary to treat it with metallic ions with 
bacteriostatic nature, such as silver, ${ }^{1-4}$ copper $^{4-8}$ and zinc. ${ }^{1,9,10}$ Among them, copper is one of the most promising because of its biocompatibility and high affinity for the pathogenic microorganisms.

Copper ions in the small quantities are essential for various metabolic processes in most of the living organisms, while the higher amounts are potentially toxic. There are three primary mechanisms for the disinfectant activity of copper ions. First, metal ions bind to proteins and deactivate them. Second, metal ions can interact with microbial membrane, which causes structural change and permeability. Finally, metal ions interact with microbial nucleic acids and thus prevent microbial replication. ${ }^{5,11}$

The research on heavy metal/clay mineral surface interactions is still of great interest because of the well-known toxicity of heavy metal ions and the need for removal of these metals from aqueous solutions. ${ }^{12,13}$ On the other hand, the research on the bactericidal properties of heavy metal exchanged montmorillonite (MMT) has increased interest since antibiotic treatment is becoming obsolete, as the overuse of antibiotics has led to an increase of bacteria resistant to antibiotics. $^{14}$

In recent years, clay mineral-based antibacterial complexes have been prepared by a series of processes between the clay minerals and antibacterial substances. Recently, Rivera-Garza et al. reported the elimination of the pathogenic microorganisms, E. coli and Enterococcus faecalis from water by silver-loaded clinoptilolite/heulandite mineral. They found that antibacterial activities of the exchanged samples were a function of exchange level against Pseudomonas aeruginosa and E. coli. ${ }^{15}$ In another work, a vermiculite-copper hybrid material shows strong antibacterial action against $S$. aureus. ${ }^{16}$

Guo et al. studied the adsorption properties of $\mathrm{Cu}^{2+}$ loaded montmorillonite $(\mathrm{Cu}-$ MMT) clays for E. coli $\mathrm{K}_{88}$. Their methods for preparation of this composite were mixing and ion exchange of MMT and $\mathrm{Cu}^{2+}\left(\mathrm{CuSO}_{4}{ }^{5} \mathrm{H}_{2} \mathrm{O}\right)$ in solution. ${ }^{6}$ Bagchi et al. synthesised copper nanoparticle based clay composite by in-situ reduction of a copper ammonium complexion. They evaluated the antimicrobial activity of the composite against E. coli, S. aureus, P. aeruginosa and E. faecalis. ${ }^{7}$ M. F. Santos evaluates the possibility of incorporating antibacterial properties in bentonite minerals by applying the ion exchange process. ${ }^{3}$ These metals/clay composites usually prepared by ion exchange of positively charged metal ions and alkali ions present in a surface layer of clay or by synthesis of nanoparticles and immobilisation them on the clay by various techniques such as ion exchange processes and sol-gel. ${ }^{1,5,6,8,9,16}$ Nevertheless, many of these techniques typically entail multiple steps combined with ultrasonication and stirring that take long hours or even days followed by chemical reduction of the precursor metal salts. 
Despite the fact that the MMT surface is poorly covered by usual mentioned process, ${ }^{4}$ the diffused copper to MMT structured via alkaline ion exchange are strong enough to form very stable and durable copper/ MMT nanocomposites. Furthermore, this method is fast and simple. In addition, preparation of $\mathrm{Cu}-\mathrm{MMT}$ by this method only requires an oven and a salt containing the doping ions. Metal-alkali ion exchange in glass has been widely used to dope silicate glasses. The procedure is done by immersing the substrate in a molten salt bath containing the dopant ions, which replace alkali ions of the substrate matrix. Ion exchange is carried out by replacing monovalent alkali ions present in a surface layer of a glass substrate with different ions from a molten salt bath.

To the authors' knowledge, there have been no studies dedicated to antibacterial by alkaline ion exchange with Copper. The aim of this paper is to characterise and evaluate the antibacterial properties of MMT-Cu nanocomposite prepared via alkaline ion exchange method.

\section{EXPERIMENTAL}

\subsection{Materials}

Bentonite clay (Na-montmorillonite) used as the solid support for copper was obtained from Kanisaz Jam Company (Rasht, Iran). All reagents were of analytical grade and were used as received without further refinement. All aqueous solutions were prepared using distilled water. Muellerhinton agar broth and nutrient agar were purchased from Merck. The bacterial strains used for the antibacterial activity were Gram-negative E. coli (PTCC 1270) and Grampositive S. aureus (PTCC1112) which were obtained from the Iranian Research Organization for Science and Technology.

\subsection{Alkaline Ion Exchange with Copper}

Bentonite were submitted to an ion exchange process by immersion to melts of $\mathrm{CuSO}_{4} \cdot 5 \mathrm{H}_{2} \mathrm{O}$ at $550^{\circ} \mathrm{C}-560^{\circ} \mathrm{C}$ for $10,20,40,60$ and $90 \mathrm{~min}$. This operation was done using $5 \mathrm{~g}$ of bentonite and $5 \mathrm{~g}$ of $\mathrm{CuSO}_{4} \cdot 5 \mathrm{H}_{2} \mathrm{O}$. After the ion exchange, the bentonite was adequately washed with distilled water and sanitation. The principal aim of this step was to dissolve any compound that was not contained in the montmorillonite. After dissolution, the bentonite was dried in an oven.

\subsection{Characterisation}

Synthesised samples were analysed by X-ray diffractometry (XRD) (Philips PW 1050). The patterns were registered in the $2 \theta$ range from $10^{\circ}$ to $60^{\circ}$ with a 
scanning step size of $0.05^{\circ}$. MMT clay was used as the reference. The morphology of the molecules was investigated by scanning electron microscope (LEO 1430VP, Germany). Absorption spectra of MMT and Cu-MMT nanocomposites was measured by a UV-visible diffusive reflectance spectrophotometer (Sinco S4100, Korea), in the wavelength range 200-1000 nm.

\subsection{Antibacterial Activity}

The antibacterial activity of the samples was studied by plate count technique on E. coli and S. aureus. Typically, $50 \mathrm{mg}$ of powder samples (MMT and Cu-MMT nanocomposites) was added to cultures of bacteria in $5 \mathrm{ml}$ sterile Muellerhinton broth. The cultures were then incubated at $37^{\circ} \mathrm{C}$ on a rotary shaker for $24 \mathrm{~h}$. Growth inhibition with time was followed by plating $100 \mu \mathrm{l}$ of the treated cultures on nutrient agar plates. Bacterial colonies were counted and compared with control after $24 \mathrm{~h}$ incubation at $37^{\circ} \mathrm{C}$. The whole experiment was repeated twice to reproduce the data. The antibacterial effect was calculated using the:

$$
\operatorname{Mortality}(\%)=\frac{B-C}{B} \times 100
$$

where $B$ is the mean number of bacteria in the control samples (CFU/sample) and $\mathrm{C}$ is the mean number of bacteria in the treated samples (CFU/sample).

\subsection{Leaching Test}

In order to evaluate the stability of the nanocomposites, leaching tests were performed. For each composite material, $0.2 \mathrm{~g}$ was immersed in $10 \mathrm{ml}$ of distilled water and vigorously shaken in a water-bath shaker $\left(30^{\circ} \mathrm{C}, 200 \mathrm{rpm}\right)$ for 3 and 6 h. Supernatant from each test tube was collected after 3 and $6 \mathrm{~h}$ by centrifugation at $10000 \mathrm{rpm}$ for $10 \mathrm{~min}$. Copper ion release from the $\mathrm{Cu}-\mathrm{MMT}$ nanocomposites was qualitatively determined by using the atomic absorption spectroscopy analysis.

\section{RESULTS AND DISCUSSION}

Appearance and colour of the parent bentonite were white (Figure 1). Alkaline ion exchange of the bentonite by copper changed the colour of bentonite from grey for 5 min treated sample to cream for treating sample for longer times. It appears that this variation of colour goes up from the amount of loaded or ion exchanged copper onto the bentonite. 


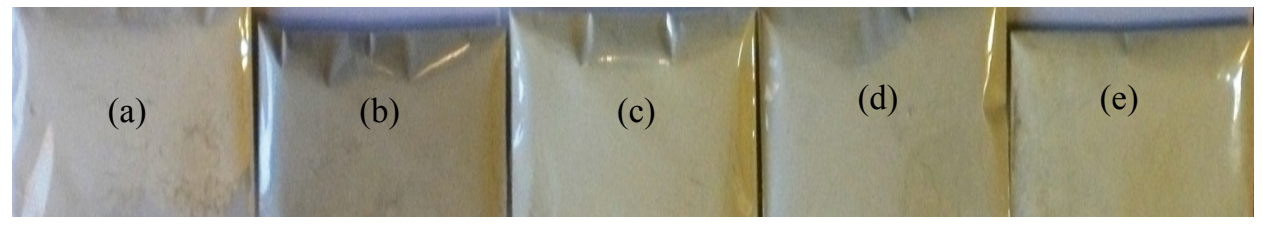

Figure 1: Photography of the parent bentonite (a), and ion exchanged bentonite with copper sulfate for $10 \mathrm{~min}(\mathrm{~b}), 20 \mathrm{~min}$ (c), $40 \mathrm{~min}$ (d) and $60 \mathrm{~min}(\mathrm{e})$.

\subsection{Diffusive Reflectance Spectra}

The formation of copper nanoparticles in the bentonite mineral system was first observed by UV-visible absorption spectra studies (Figure 2). The absorbance band in a UV visible spectrum of $\mathrm{CuSO}_{4}$ shows two bands around 247 and 310 $\mathrm{nm}$. These bands are attributed to a charge transfer transition of inter layer tetrahedral and octahedral atoms. ${ }^{19}$ After alkaline ion exchange, the band of 247 $\mathrm{nm}$ disappeared and it has not been observed in $\mathrm{Cu}$-MMT nanocomposites anymore. Absorption spectroscopy of bentonite revealed a characteristic band around $310 \mathrm{~nm}$. Ion exchange of $\mathrm{Cu}^{2+}$ loaded bentonite results in formation of $\mathrm{Cu}-\mathrm{MMT}$ nanocomposites. Evidence for this comes from the change in composite colour (Figure 1). This band red shifted between 3 and $12 \mathrm{~nm}$ (Figure 3 ) depending upon the particle size and shape. This means that increasing time of ion exchanged caused more diffused copper ion and coalescence of forming particles to each other.

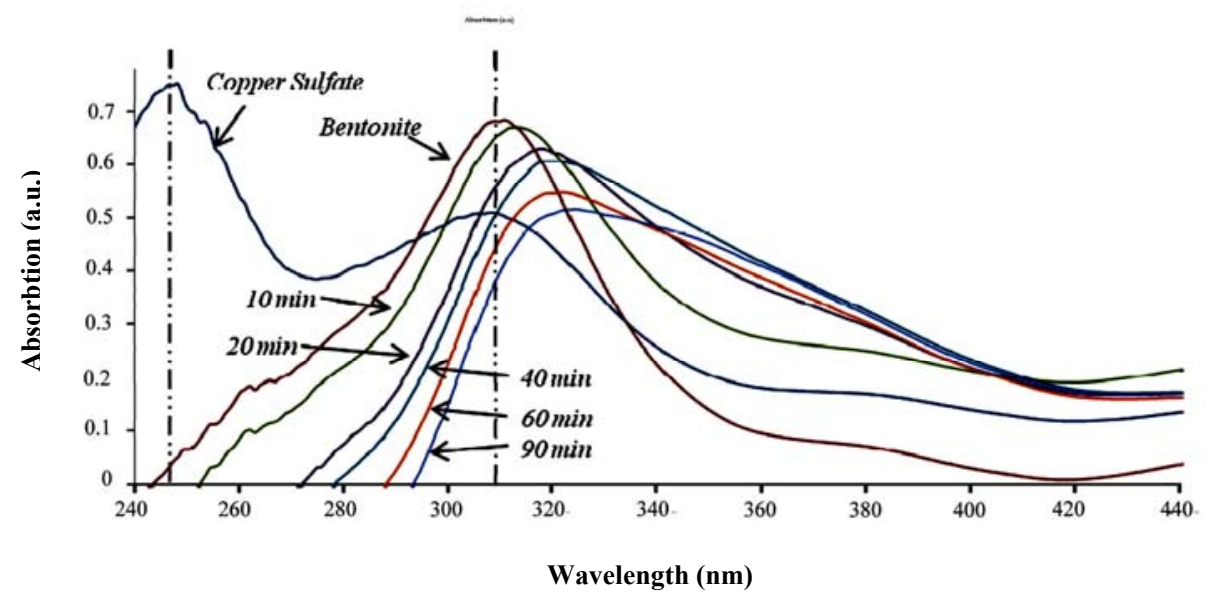

Figure 2: Diffusive reflectance spectra of prepared samples. 


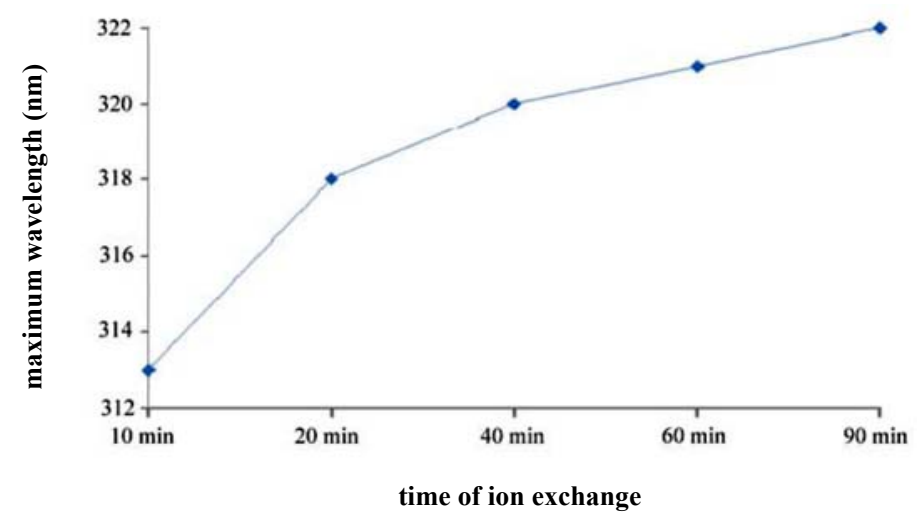

Figure 3: The wavelength of maximum absorbance of prepared samples.

Figure 4 shows the differences between maximum absorbance and the right shoulder (10 nm after the maximum wavelength of peak). As we can see from this figure, the absorbance of the right shoulder of each composite increased, thus the difference decreased. This means that the peak broadened by increasing ion exchange time. The broadness of the absorption band probably arises from the wide size distribution of copper nanoparticles. As the ion exchange time increased, the absorbance band slowly broadened in the copper-doped bentonite nanocomposites. Therefore, for an ion exchange time of less than $40 \mathrm{~min}$, the change in distribution of copper nanoparticles is large, but beyond this time, the distribution becomes small.

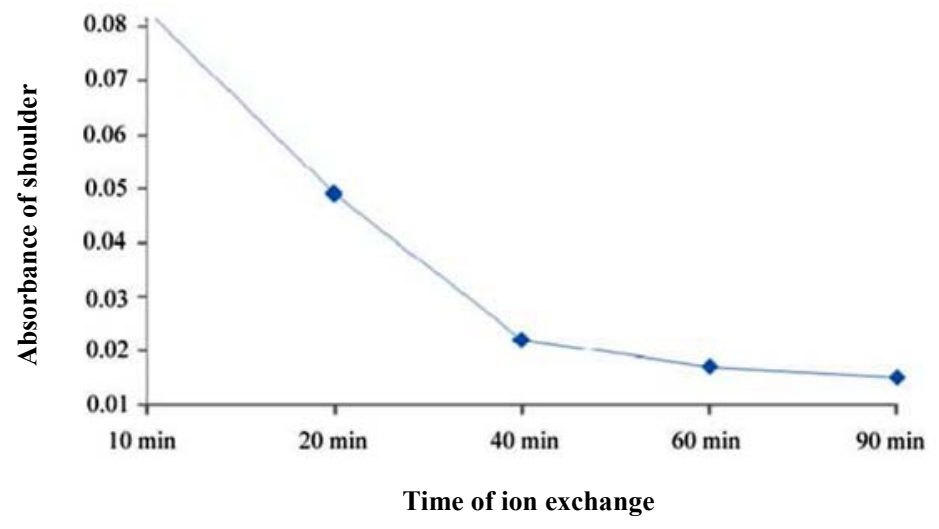

Figure 4: The absorbance of right shoulder of prepared samples. 


\subsection{SEM Analysis}

The scanning electron micrograph (SEM) of MMT in Figure 5(a) shows the typical layered structure with numerous flakes of clay particles with a sheet-like morphology. In $\mathrm{Cu}-\mathrm{MMT}$, the clay structure is maintained with some changes. As can be seen from Figure 5, after alkaline ion exchange of MMT for $10 \mathrm{~min}$, the porosity of clay obviously decreased. This is because of the filling of the pores of MMT by copper molecules. In this sample, copper still did not have enough time for diffusion to the inner MMT structure and only situated on the surface of MMT. Increasing the ion exchange time to 20 min caused the composite to return to the flaks-like structure, whereas the shape of the sample of $20 \mathrm{~min}$ is approximately the same with parent MMT. More flaks and more porosity can be seen in longer ion exchanged samples. This is because of the diffusion of copper to the inner layer of MMT and opening of crack on its surface. Thus, more layers can be seen on the composite surface.

In previous works, the treated clay contains heterogeneous particles on its surface. ${ }^{8,13,16}$ On the other hand, metallic nanoparticles typically cover surfaces of alumino-silicate minerals. The authors' results of these studies obviously differ in compression. As can be seen from Figure 5, no particles are formed on the MMT surface after alkaline ion exchange. However, the structure of MMT has been changed and more flaks appeared. As a result, more porosity can be seen in the ion exchanged samples. 




(a)

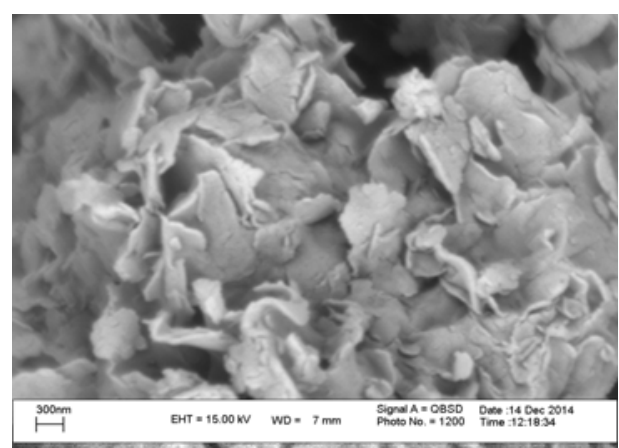

(c)

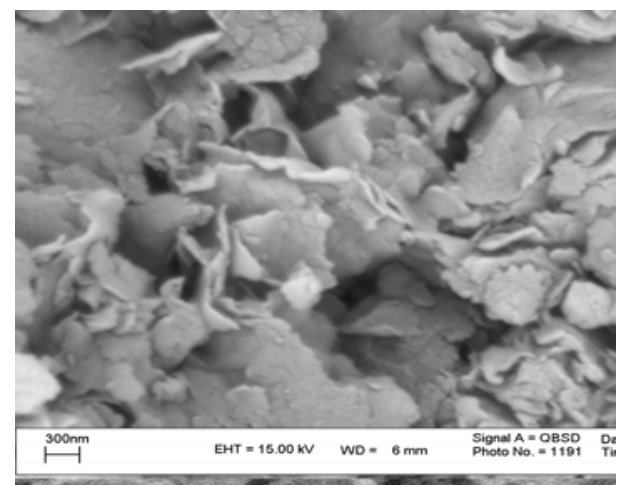

(e)



(b)

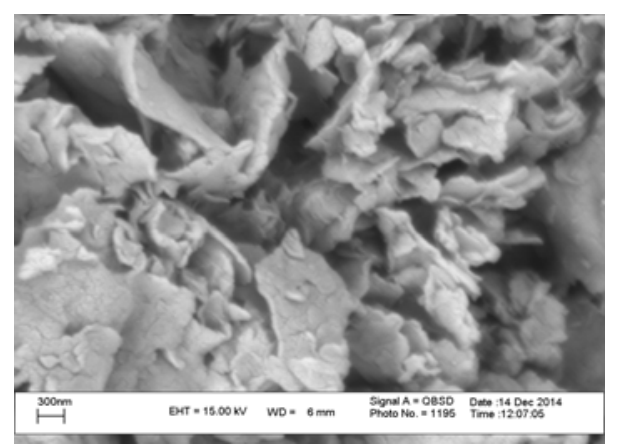

(d)

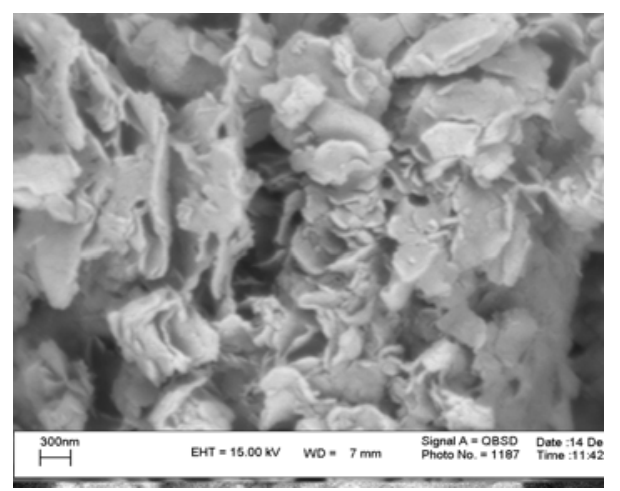

(f)

Figure 5: SEM image of the parent MMT (a), ion exchanged for $10 \mathrm{~min}$ (b), $20 \mathrm{~min}$ (c), $40 \min (d), 60 \min (e)$ and $90 \min (f)$. 


\subsection{XRD Analysis}

The XRD patterns collected are presented in Figure 6. The patterns were smoothed by using an eight-point average, in an attempt to minimise the appearance of background noise. The reflections on $2 \theta$ values of about $35.17^{\circ}$ (111) and $61.89^{\circ}(113)$ correspond to copper oxide $(\mathrm{CuO})$. The appearance of the oxide reflection in the diffractogram suggested the presence of $\mathrm{CuO}$ structure intercalated within the clay mineral layers. The intensity of the reflection corresponding to the $\mathrm{CuO}$ increases with the increase in the loading within the layered silicate. As shown by the sharp and more intense band, the degree of crystallinity increases with copper concentrations.

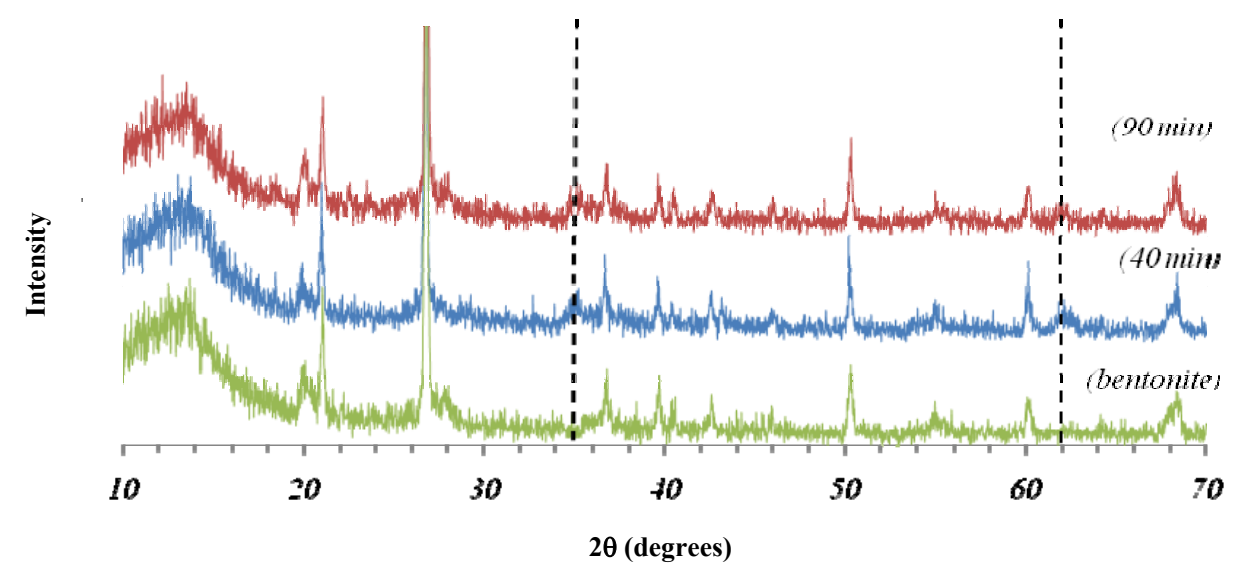

Figure 6: X-ray diffraction pattern of parent bentonite and Cu-MMT nanocomposites.

\subsection{Antibacterial Assay}

The influence of the time of ion exchange on the antibacterial activity of the sutures was studied against Gram-negative E. coli and Gram-positive S. aureus. The effects of different ion exchange time on the antibacterial properties of the $\mathrm{Cu}-\mathrm{MMT}$ nanocomposites were presented in Table 1 . The antibacterial trial showed that MMT had no antibacterial activity. The antibacterial activity of $\mathrm{Cu}-$ MMT tested for E. coli and S. aureus showed positive results with high mortality. The tests exhibited more than $99.98 \%$ mortality against E. coli, whereas it showed $100 \%$ mortality against $S$. aureus. 
Table 1: Mortality percentage of Cu-MMT against E. coli and S. aureus.

\begin{tabular}{crr}
\hline \multirow{2}{*}{$\begin{array}{c}\text { Ion exchange } \\
\text { time (min) }\end{array}$} & \multicolumn{2}{c}{ Mortality (\%) } \\
\cline { 2 - 3 } & E. coli & S. aureus \\
\hline 10 & 99.96 & 85.23 \\
20 & 99.97 & 95.35 \\
40 & 99.98 & 100 \\
60 & 99.98 & 100 \\
90 & 99.99 & 100 \\
\hline
\end{tabular}

The antibacterial property of copper nanoparticle is well researched and the mechanism of its action is generally found to be a combination of several types of interactions like membrane perforation, DNA damage, protein denaturation, etc. However, they do not equally affect all microorganisms. As studied earlier, bacterial susceptibility to nanoparticles depends on several factors like bacterial strain, nanoparticle type and size, the nature of growth media and initial cell concentration. In general, Gram-negative organisms are more resistant to the growth inhibiting effect of copper ions/nanoparticles than Gram-positive ones. ${ }^{7}$

Copper-based antimicrobial materials could easily compete with comparable silver-based materials, and would be much cheaper. ${ }^{16}$

\subsection{Copper Ion Release Assay}

Table 2 shows the copper amount released into the aqueous media as a function of the contact time between phases. Maximum release of copper ion was observed at around $6 \mathrm{~h}$ for $90 \mathrm{~min}$ sample with a corresponding increase in mortality rate for bacterial cell. The copper ion released from the composite may come from the nanoparticles either adsorbed on clay surface or suspended in the solution after desorption. The obtained results indicate, that the materials do not pose any danger for drinking water treatment since the leached metals were very small and in acceptable concentrations.

Table 2: Copper concentration in water at different contact times between the Cu-MMT and the aqueous media.

\begin{tabular}{lccccc}
\hline \multirow{2}{*}{ Ion exchange time (min) } & \multicolumn{4}{c}{ Copper concentration in water (ppm) } \\
\cline { 2 - 6 } & & MML & 40 & 60 & 90 \\
\hline \multirow{2}{*}{ Contact time (h) } & 3 & 0 & 0.02 & 0.02 & 0.21 \\
& 6 & 0 & 0.07 & 0.05 & 0.38 \\
\hline
\end{tabular}


The copper ion released from the alkaline ion exchanged Cu-MMT is obviously lower than previous studies. ${ }^{8,15}$ This can be attributed to diffusion of copper to the MMT structure instead of attachment of copper nanoparticles to MMT. The advantage of this is that the antibacterial property of $\mathrm{Cu}-\mathrm{MMT}$ composite would be longer.

The released $\mathrm{Cu}^{2+}$ would act directly on the bacteria adsorbed on the surface of the $\mathrm{Cu}-\mathrm{MMT}$, instead of into the medium and indirectly on the bacteria. In other words, the active $\mathrm{Cu}^{2+}$ density on mineral surface was much higher than its concentration in the solution. In summary, two possible mechanisms for the antibacterial activity of $\mathrm{Cu}-\mathrm{MMT}$ were proposed. One involves the adsorption of the bacteria from solution and immobilised on the surface of the Cu-MMT. Alternatively, $\mathrm{Cu}^{2+}$ could disassociate from the clay surface and directly exert its antibacterial effect on the bacteria. ${ }^{8}$

\section{CONCLUSION}

The aim of this study was to evolutionise the antibacterial activity of copperdoped montmorillonite nanocomposites synthesised by alkaline ion exchange processes in media containing molten copper sulfate at $550^{\circ} \mathrm{C}$ temperature. The SEM results indicated the diffusion of copper to the inner layer of montmorillonite and opening of presenting cracked on its surface. The XRD analysis showed that the copper ions fully incorporated into the montmorillonite. Quantitative test in liquid media clearly showed that copper-doped samples had viable cell reduction ability for testing strains. The excellent antimicrobial activity of the composites was observed on $S$. aureus. In addition, the composite showed good stability in water. In the present form the clay composite shows good promise for use in water treatment.

\section{REFERENCES}

1. Motshekga, S. C. et al. (2013). Microwave-assisted synthesis, characterization and antibacterial activity of $\mathrm{Ag} / \mathrm{ZnO}$ nanoparticles supported bentonite clay. J. Hazard. Mater., 15(262), 439-446.

2. Dong, F. et al. (2005). Preparation and antimicrobial ability of natural proous antibacterial material. J. Cent. South. Univ. Tech., 12(4), 370375.

3. Santos, M. F. et al. (2011). Bactericidal properties of bentonite treated with $\mathrm{Ag}^{+}$and acid. Int. J. Min. Process., 100(1), 51-53. 
4. Top, A. \& Ulku, S. (2004). Silver, zinc, and copper exchange in a Naclinoptilolite and resulting effect on antibacterial activity. Appl. Clay Sci., 27(1), 13-19.

5. Stanic, V. et al. (2010). Synthesis, characterization and antimicrobial activity of copper and zinc-doped hydroxyapatite nanopowders. Appl. Surf. Sci., 256(20), 6083-6089.

6. Guo, T. et al. (2011). Adsorptive property of $\mathrm{Cu}^{2+}$-loaded montmorillonite clays for Escherichia coli $\mathrm{K}_{88}$ in vitro. J. Environ. Sci., 23(11), 1808-1815.

7. Bagchi, B. et al. (2013). In situ synthesis and antibacterial activity of copper nanoparticle loaded natural montmorillonite clay based on contact inhibition and ion release. Coll. Surfaces B: Bioint., 108, 358-365.

8. Hu, C. H., Xu, Z. R. \& Xia, M. S. (2005). Antibacterial effect of $\mathrm{Cu}^{2+}-$ exchanged montmorillonite on Aeromonas hydrophila and discussion on its mechanism. Vet. Microb., 109 (1-2), 83-88.

9. Pouraboulghasem, H. Ghorbanpour, M. \& Samaneh Lotfiman, R. S. (2016). Synthesis, characterization and antimicrobial activity of alkaline ion-exchanged $\mathrm{ZnO} /$ bentonite nanocomposites. J. Cent. South. Univ. Tech., 23(4), 787-792.

10. Shao-Zao, T. et al. (2008). Preparation and characterization of the antibacterial $\mathrm{Zn}^{2+}$ or/and $\mathrm{Ce}^{3+}$ loaded montmorillonites. Chin. J. Chem., 26(5), 865-869.

11. Phan, T.-N. et al. (2004). Physiologic actions of zinc related to inhibition of acid and alkali production by oral streptococci in suspensions and biofilms. Oral Microbiol. Immun., 19(1), 31-38.

12. Bertagnolli, C., Kleinübing, S. J. \& da Silva, M. G. C. (2011). Preparation and characterization of a Brazilian bentonite clay for removal of copper in porous beds. Appl. Clay Sci., 53(1), 73-79.

13. Kaya, A. \& Oren, A. H. (2005). Adsorption of zinc from aqueous solutions to bentonite. J. Hazard. Mater. B, 125(1-3), 183-189.

14. Özdemir, G., Limoncu, M. H. \& Yapar, S. (2010). The antibacterial effect of heavy metal and cetylpridinium-exchanged montmorillonites. Appl. Clay Sci., 48(3), 319-323.

15. Rivera-Garza, M. et al. (2000). Silver supported on natural Mexican zeolite as an antibacterial material. Microporous Mesoporous Mater., 39(3), 431-444.

16. Drelich, J. et al. (2011). Vermiculite decorated with copper nanoparticles: Novel antibacterial hybrid material. Appl. Surf. Sci., 257(22), 9435-9443. 